and specificity had to be calculated on a theoretical population. This was developed by extrapolation from the prevalence of symptoms and signs in a random sample of well babies examined at home at varying times after birth and from children who had been referred for admission to a paediatric unit.

Two assumptions have been made in creating this theoretical population. The first is that those children who are referred for admission are the sickest. We know that general practitioners vary in their propensity to refer patients to hospital, and parents vary in their ability to cope with sickness at home. For this reason we cannot be certain, without assessing sick children who are being cared for at home, that there are not many children who never reach hospital but who have similar symptoms and signs to those of children who are referred. The second assumption is that the sickest children will form the $2 \%$ of the population who are seen in hospital. Again, without a detailed community survey of all children within a defined population it is difficult to know whether this assumption is correct. Common sense leads us to expect that admissions vary with the season and by the social class distribution of the population. The difficulties that the researchers faced in developing the Baby Check were considerable, and the sensitivity and specificity that they quote for their test should be regarded with caution.

Is the Baby Check easy to use? Although it is dauntingly long, the explanations on how to interpret the symptoms and elicit the physical signs are excellent. Field trials report that mothers and their general practitioners were satisfied with the booklet. It should be borne in mind, however, that the sample of mothers in whom these trials were conducted contained a high proportion of well educated people and even in this sample the uptake was not good. The results might not be nearly so favourable in a less advantaged population, and further field trials are needed in this group.

The Baby Check may be of great value to a general practitioner faced with a sick baby whom he or she wants to look after at home. In such a case the parents would have a systematic way of assessing their child that would relieve anxiety, both their own and that of the general practitioner. The Baby Check does not address the problem of the sudden infant death syndrome, in which major and minor signs of illness are neither a sensitive nor specific indicator of sudden unexpected deaths of infants and have no predictive value. ${ }^{5}$

Consultant Senior Lecturer in General Practice,

CHRIS WATKINS

General Practice Unit,

Department of Epidemiology and Public Health,

University of Bristol,

Bristol BS8 2PR

1 Morley CJ, Thornton AJ, Cole TJ, Hewson PH, Fowler MA. Baby Check: a scoring system to grade the severity of acute systemic illness in babies under 6 months old. Arch Dis Child 1991;66:100-5. Thornton AJ, Morley CJ, Green SJ, Walker KA, Rennie JM. Field trials of the Baby Check score card: mothers scoring their babies at home. Arch Dis Child 1991;66:106-10.

Morley CJ. Thornton AJ, Green SJ, Cole TJ. Field trials of the Baby Check score card in general practice Arch Dis Child 1991:66:111-

practice. Arch Dis Child 1991;66: 111-4.
Thornton AJ, Morlev CJ, Cole TJ, Green SJ, Walker KA, Rennie JM. Field trials of the Baby Check score card in hospital. Arch Dis Child 1991;66:115-20.

Gilbert RE, Fleming PJ, Azaz Y, Rudd P. Signs of illness preceding sudden unexpected deaths in infants. BMJ 1990;300:1237-9.

\title{
The politics of change
}

\section{The take off was never going to be smooth}

The occupational disease of politicians, it is often argued, is myopia - that is, an inability to see beyond the next general election. It is not a criticism that can be levelled against the authors of the NHS reforms. On the contrary, the charge against them must be that their eyes were so firmly fixed on the distant horizon that they ignored the political pot holes on the road towards their objectives. Not surprisingly, ministers have stumbled. Not surprisingly, either, the opposition has gleefully seized on every slip: the announcement of redundancies by Guy's and Lewisham Trust ${ }^{1}$ came providentially just as the poll tax issue was slipping away. It is a pattern that is likely to be repeated with increasing frequency-and stridency - as the general election approaches.

Given the scale and complexity of the NHS, probably not a week has gone by since 1948 when there has not been some problem or scandal somewhere waiting for exposure. The difference now is that the NHS reforms provide a focus for discontent; everything can be blamed on them. Indeed, there may even be incentives to exaggerate them. This is not to argue that the implementation of the NHS reforms is unproblematic. It is to suggest, however, that if we are to identify and isolate their impact we must first try to understand the political dynamics of change: the reason why we might expect political turbulence even if the introduction of the reforms had been handled differently or with a more generous injection of funds to ease the pains of transition.

The main reason for turbulence is simple. It is that the NHS reforms, quite deliberately, represent a challenge to the status quo. They are meant to force a re-examination of existing clinical practices and patterns of organisation. The point emerges strongly from Enthoven's influential paper, ${ }^{2}$ which helped to crystallise many of the ideas that shaped the reforms. In this he argued, following other commentators, ${ }^{3}$ that the NHS's problems stemmed from "rigidity." Organisational innovation had lagged behind clinical innovation; even in the case of clinical innovation, incentives to generalise best practices were weak. Given this diagnosis, implicitly endorsed by the government, ${ }^{+}$it is not surprising that the cure is seen as threatening. The balance of power-between consultants and managers and between hospitals and general practice-is shifting. New ways of doing things have to be learnt; inherited investments in organisational knowledge have to be written off. The process is understandably painful for many of those concerned, just as it has been painful for teachers in schools and universities, where a similar process of change has been going on. Much of the reaction to the NHS reforms therefore tells us nothing (for good or bad) except that resistance to change is as inevitable as it is predictable. Indeed, it was predicted by Enthoven ${ }^{2}$ :

Politicians face powerful disincentives to attempting significant change. The benefit from any serious attempt to improve things would be gradual, not clearly visible before the next election. ... It is hard for non-specialist voters to distinguish image from reality in the short run. But any serious efficiency-improving change risks being attacked as 'downgrading the quality of care' by threatened provider groups, or being blasted by the left as 'tampering with the NHS.'

There are other grounds for predicting resistance to change if this entails any shift in policies or resources. Existing 
institutions create their own constituencies of support, among both staff and patients. They are visible, concentrated, and organised interest groups. They can bring out their supporters. In contrast, the beneficiaries of change may be diffuse, ill organised, and often difficult to identify. ${ }^{5}$ The argument can be simply illustrated. Any attempt to shift resources from curative to preventive services inevitably means antagonising those who either provide or benefit from curative services in order to benefit future generations: the future has no constituency that can be mobilised as a counterweight to existing interests threatened by change. In this sense there is a built in asymmetry or imbalance that loads the dice against reformers.

There is a further asymmetry special to the NHS. This is the asymmetry between London and the rest of the country. The concentration of teaching hospitals in London and the resultant disproportionate share of resources that has gone to the capital's health services have been a matter of concern throughout this century. ${ }^{6}$ The NHS reforms have, in this as in other respects, simply given new visibility - and added edge - to an old issue. This stems from the division between purchasers and providers (whether or not they are trusts). It is for the purchasers to buy the services required by their populations; it is for the providers to provide them to the right standard, at the right price. In other words, the emphasis has switched from the maintenance of institutions to the provision of services. Hence the dilemma of London teaching hospitals, and others. The logic of the new system is that if they can provide the appropriate services at the appropriate price they will survive. If not, they may have to adjust the scale and scope of their activities: a process that, clearly, has already begun-so setting off the latest political explosion.

It is precisely the distinction between services and institutions that may, furthermore, provide the key for any attempt to disentangle the political and substantive impact of the NHS reforms. Institutions matter in the new system, it may be argued, only to the extent that they are required to provide specific services, although health authorities would obviously be very unwise to ignore the effects of damaged morale on the provision of those services. It follows, then, that the real test of what is happening in the NHS now must surely be the way in which the purchasing authorities are commissioning services and monitoring their delivery. And if this is so, attention should shift to the purchasing agreements and contracts that have been issued by the health authorities. As far as services to patients are concerned, these are the crucial documents rather than the business plans of trusts (though that should be no reason for frustrating public accountability by making such trust documents inaccessible to parliamentary scrutiny).

It is the purchasing agreements and contracts that should answer the question of what is being provided to whom and provide information about changes in levels of service, access, availability, and standards over time. For it is these that should specify the quantity and quality of services being delivered to a particular population. The first batch of agreements and contracts, drawn up in a rush and designed to minimise turbulence, probably fail to specify precise enough benchmarks against which to measure change - whether for better or worse. But if we are to start making sense of what the reforms are doing to the NHS, cutting through the political noise, then clearly there must be an intensive and urgent push in this direction. If the government wants its record to be judged at the next general election not by the input of resources into the NHS but by the output of services it is clearly essential to have more information about the adequacy, quality, and scope of what is being provided by individual health authorities. In the absence of such information it is impossible to come to any conclusive judgment about either the total budget or the significance of cutbacks in individual hospitals.

Professor of Social Policy,

RUDOLF KLEIN

Centre for the Analysis of Social Policy,

School of Social Sciences,

University of Bath BA2 7AY

Groves T. Guy's and Lewisham Trust "sorts itself out." BMF 1991;302:1039. (4 May.)

2 Enthoven AC. Reflections on the management of the National Health Service. London: Nuffield Provincial Hospitals Trust, 1985.

3 Klein R. The politics of the NHS. London: Longmans, 1983.

4 Secretaries of State for Health, Wales, Northern Ireland, and Scotland. Working for patients. London: HMSO, 1989. (Cmnd 555.)

Marmor TR. Political analysis and American medical care. Cambridge: Cambridge University Press, 1983.

Rivett G. The development of the London hospital system, 1823-1982. London: King Edward's Hospital Fund for London, 1986

\section{Escaping insulin dependent diabetes}

\section{Characteristic immunological changes don't invariably lead to disease}

Insulin dependent diabetes mellitus is caused by an immunologically mediated destruction of the $\beta$ cells in the islets of Langerhans. The disease process is associated with immune changes in the peripheral blood and includes the production of autoantibodies to islet cells and to insulin and increased concentrations of activated $\mathrm{T}$ lymphocytes expressing the HLA-DR antigen.' Genetic susceptibility to insulin dependent diabetes is mediated predominantly by HLA genes. ${ }^{2}$ The disease seems to result from an environmental event, possibly exposure to either a virus or a toxin, over a brief period in early childhood. ${ }^{3}$ After this event an antigen, either an islet autoantigen or a viral antigen, is presented to a $\mathrm{T}$ cell receptor by the HLA molecule. The resultant immune response leads to the destruction of most of the insulin secreting cells and finally to insulin dependent diabetes.

We used to think that this was a rapid process. But is it? Twenty five years ago Lister and colleagues showed that even in children clinical symptoms had been present for a few months before the diagnosis of insulin dependent diabetes. ${ }^{4} \mathrm{It}$ is now apparent that clinical, immunological, and metabolic changes may start years before the onset of the disease. This prediabetic period may be characterised by growth delay, ${ }^{5}$ the presence of autoantibodies to islet cell proteins including insulin $^{6}$ and a $64 \mathrm{kDa}$ protein (possibly glutamic acid decarboxylase), ${ }^{7}$ activation of T lymphocytes, ${ }^{8}$ impaired glucose tolerance, ${ }^{9}$ a decreased insulin response to intravenous glucose,${ }^{10}$ and increased fasting proinsulin concentrations. ${ }^{11}$

We have assumed that once started these changes inevitably led to diabetes, but now this also seems doubtful. Increased concentrations of activated $\mathrm{T}$ lymphocytes and autoantibodies to both islet cells and insulin have been detected in nondiabetic twins or siblings of diabetic patients, who were unlikely to develop diabetes. ${ }^{612} 13$ Furthermore, islet cell antibodies can disappear without the child developing dia- 